\title{
Clinital obserbations.
}

$\mathrm{BY}$

JAMES SYME, EsQ,

PROFESSOR OF CLINICAL SURGERY IN THE UNIVERSITY OF EDINBURGH.

\section{II.-ESOPHAGOTOMY.}

M. C., aged 45, was admitted into the hospital on the 22nd July, 1861. She stated that six days before the time of her application, while eating mutton-broth, she had suddenly felt inability to swallow, together with severe pain, from which she concluded that a piece of bone had stuck in her throat. Under this impression, she had applied for assistance, and been treated by the introduction of probangs or other instruments, without success, so that her distress remained unrelieved, and became complicated with fits of dyspnœa, which repeatedly threatened to prove fatal. On examination, I found her in the state described, with a very anxious expression of countenance, and slight general fulness of the neck, which was not discoloured or otherwise altered, but felt somewhat tender under pressure. Having introduced the long curved forceps, without being able to touch the foreign body, but feeling satisfied, from the circumstances just mentioned, that there was one present; and fearing, that if allowed to remain, it would cause suppuration, if indeed it had not already done so, I considered it necessary to adopt the only effectual mode of affording relief, by performing the operation of œsophagotomy.

With this view, having administered chloroform, I made an incision as if for ligature of the carotid artery, exposed the edges of the sterno-mastoid and sterno-thyroid muscles, and then opened the deep fascia of the neck, from under which a small quantity of purulent matter escaped. Introducing my finger through the narrow passage thus detected, I carried it upwards and backwards to the posterior part of the gullet, where a piece of bone was felt protruding from the canal. The requisite dilatation having been made, I guided in a pair of polypus forceps, and extracted a piece of mutton bone, extremely thin, but nearly an inch square.

The operation was performed on a Thursday, and on Friday the patient seemed to be doing well; but on Sunday, I was told that she had become delirious on Saturday, and appeared to be sinking. Upon visiting her, I found the hands blue and perfectly cold, with the faintest possible thrill instead of a pulse, so that the case had certainly a most hopeless aspect. It occurred to me, however, that the symptoms might possibly proceed from hunger, as the patient, during a whole week, had not been able to swallow at all, and since the bone was removed had done so very imperfectly, from the milk and other fluids given to her escaping in great part by the wound; I therefore, by means of a catheter, introduced from the mouth into the œsophagus, immediately injected some beef-tea, with wine. In the course of half an hour, there was, in all respects, a decided improvement, which, through a continued employment of the same means, repeated regularly at proper intervals, gradually increased, until recovery was completed at the end of a fortnight.

\section{㻎ecturtes}

ON THE

\section{DIAGNOSIS AND TREATMENT OF DISEASES OF WOMEN.}

\author{
DELIVERED AT ST. MARY'S HOSPITAL MEDICAL \\ SCHOOL. \\ BY
}

GRAILY HEWITT, M.D.LoND., M.R.C.P.,

PHYSICIAN TO THE BRITISH LYING-IN HOSPITAL; LECTURER ON AIDWIFEIY AND DISEASES OF WOMEN AND CHILDREN AT ST. MARY'S HOSPITAL NEDICAL SCHOOL.

\section{Disorders of Menstruation (continued).}

Genthemen,-There are two classes of cases, under one of which all disorders of menstruation likely to present themselves for examination can be included-1. Those in which there is a minus state of the discharge; and 2 . Those in which the quantity being excessive, or above what usually obtains, it may be considered as being in a plus state.

\section{1.-Minus Conditions of the Catamenia: Dis- CHARGE EITHER ABSENT OR LESS THAN USUAL.}

a. The series of cases which may be first examined are those in which menstruation is not, and never has been, present. We are here concerned, not with those cases in which there has been a slight sanguineous discharge from the generative organs, but with those in which there has been none at all. The first point which it is necessary to determine, in endeavouring to ascertain the cause of the nonappearance of the menstrual secretion, is, Are the organs essential to the performance of this function actually present? If the ovaries be absent, no menstrual discharge can take place; and the like holds good if, the ovaries being present, the uterus be absent. Cases coming under either of these categories are exceedingly rare. The absence of the ovaries would coexist with absence of the external signs of puberty. The breasts, under such circumstances, would be small and undeveloped. Absence of sexual desire and of other feminine characteristics might be expected to be observed. Women who have had the ovaries artificially removed when young are said to have acquired a masculine voice, and even a profusion of hairs on the chin and face, resembling the beard of the man. Absence of the uterus, or what practically amounts to the same thing-extremely rudimentary formation of this organ-is, there is reasou for believing, an occurrence of rather less rarity than absence of the ovaries. In a case which came under my own observation, the catamenia were quite absent; the sexual inclination was very slight, but still present; and the breasts rather small. The ovaries were probably present; but, on physical examination, no uterus could be detected.

Another congenital defect-viz., absence of the vagina-may prevent the appearance of the menstrual flow; but absence of the vagina usually betokens absence or very rudimentary formation of the uterus. There are very few instances in which the flow does not appear because the vagina is deficient-a fact important to be borne in mind in reference to proposed operations for the removal of the defect in question. 